\title{
Assessment of the Environmental Impacts of COVID-19 in Urban Areas-A Case Study of Iran
}

\author{
Fatemeh Rezaeitavabe ${ }^{*}$, Majid Sartaj2 ${ }^{2}$, Mohammad Asadi Tokmedash ${ }^{3}$, \\ Nasser Talebbeydokhti ${ }^{1}$ \\ ${ }^{1}$ Department of Civil and Environmental Engineering, Shiraz University, Shiraz, Iran \\ ${ }^{2}$ Department of Civil Engineering, University of Ottawa, Ottawa, Canada \\ ${ }^{3}$ Department of Chemical Engineering, College of Engineering, University of Tehran, Tehran, Iran \\ Email: ^msartaj@uottawa.ca
}

How to cite this paper: Rezaeitavabe, F., Sartaj, M., Tokmedash, M.A. and Talebbeydokhti, N. (2021) Assessment of the Environmental Impacts of COVID-19 in Urban Areas-A Case Study of Iran. Journal of Environmental Protection, 12, 328-344. https://doi.org/10.4236/jep.2021.125021

Received: February 3, 2021

Accepted: May 24, 2021

Published: May 27, 2021

Copyright ( 2021 by author(s) and Scientific Research Publishing Inc. This work is licensed under the Creative Commons Attribution International License (CC BY 4.0).

http://creativecommons.org/licenses/by/4.0/

\section{(c) (i) Open Access}

\begin{abstract}
The Severe Acute Respiratory Syndrome-Coronavirus Outbreak 2019 (COVID-19) has caused worldwide concern and has affected all aspects of human life. The study objective is to assess and evaluate the direct and indirect positive and negative environmental effects of COVID-19 in urban areas. Collected data for Iran as a case study is presented, comprehensively completing the dynamic effect of COVID-19 on the environment. The analysis results indicate that despite the temporarily positive effects of coronavirus on the environment, such as improvement in air quality (15\% - 20\% reduction of NO2 in Tehran), environmental noise reduction, cleaner beach and coastal areas due to implementing lockdowns, there are negative short- and long-term effects such as excessive water consumption (10\% - 40\% increase in Iranian cities), reduce in waste recycling and significant increase in both residential and medical solid waste generation $(10 \%-77 \%$ increase in medical waste generation and $10 \%-50 \%$ increase residential waste generation in Iranian cities), which leads to pollution or/and degradation of the environment (air, water and land). Moreover, with the global economic relaunching relaunch in most countries in the coming months, it could result in adverse effects such as increase in the greenhouse gas emissions. Assessment of environmental impacts, type and scale, could help for better planning and mitigation of the future pandemics.
\end{abstract}

\section{Keywords}

COVID-19, Coronavirus, Pandemic, Environmental Impacts, Iran

\section{Introduction}

Human health is closely linked to the animals and the environment. In a broad 
sense, integrated health is the result of interaction between animals, humans, and the environment. This is of great importance and an important topic in the field of ecology of infectious diseases. Nowadays, due to various factors such as increasing interaction between countries, rapidly evolving pathogens, climate change, population explosion, scarcity of food, changing human lifestyles and intensive agricultural activities, the risk of emerging and re-emerging zoonotic diseases has increased. Zoonotic disease is an infectious disease that usually spreads through an animal host but can be contracted by humans. Zoonotic diseases include a vast range of infectious diseases including bacterial, viral, parasitic and fungal diseases, which are especially associated with animal and environmental components. Interaction between these factors is critical to the understanding and studying of these diseases such as the Plague of Justinian, Middle East Respiratory Syndrome (MERS), Swine flu, severe acute respiratory syndrome (SARS), and the new Coronavirus 2019 (COVID-19). Investigating the history of infectious diseases shows that humans have been dealing with epidemic diseases for the past two millenniums (Figure 1) and early civilizations have experienced pandemic incidents. The outbreak of Justinian plague in 541, which killed millions of people, as one of the first documented incidents and the recent COVID-19 are examples of pandemics humans have faced.

Over the past two decades, it has been observed that the disastrous capacity of Coronaviruses has been continuously evolving, resulting in fatal outbreaks which cause a threat to global health. The recently emerged Coronavirus is the third most common form of $\mathrm{CoV}$ in humans and is a new type of SARS-CoV-2 virus that emerged in late December 2019 in Wuhan, China, and quickly spread to many countries all over the globe [1] [2] [3] [4] [5]. This type of disease is common between humans and animals and is often transmitted through close contact between animals and humans, causing respiratory and gastrointestinal infections. Preliminary studies showed that a food market in Wuhan, Hubei Province, China, was the main source location of the virus. The Wuhan Food Market is an example of a moist market that sells chickens, snakes, bats, and other wild animals to the public [6]. Wet markets are ideal points that act as an intermediary between humans and animals, which can be a place for the zoonotic viruses to be transmitted to humans. Then, the major modes of transmission between humans are through exposure to respiratory droplets from an infected person or contact with contaminated surfaces [1].

Coronavirus is a single-stranded virus that not only spreads among humans, but is also transmitted to a large number of animals [7]. These types of viruses were studied by Tyrell and Bynoe in 1966 for the first time [8]. Due to the spherical morphology with a shell and a surface projection such as the crown, these viruses are called Coronaviruses. In Latin, corona means crown, and four different sub-families, including alpha, beta, gamma, and delta, have been recognized so far. Alpha and beta Coronaviruses originated in mammals, especially bats, gamma and delta coronaviruses have been originated in birds and pigs [9]. Coronaviruses of beta groups including COVID-19, can cause severe illness and 


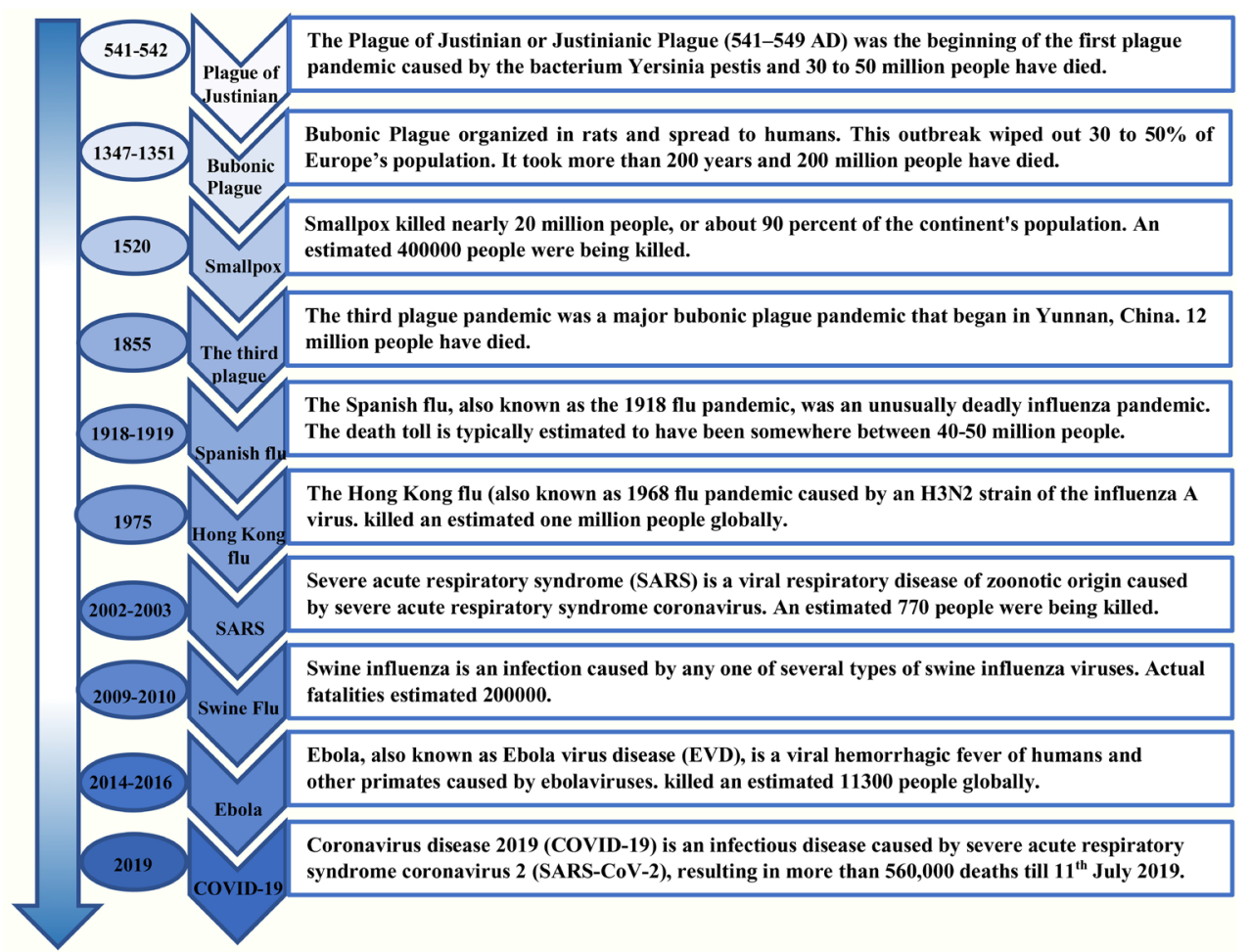

Figure 1. Examples of epidemic infectious diseases in human life history [12]-[19].

death [6]. The genome of SARS-CoV-2 is $96 \%$ identical to the bat coronavirus [10]. COVID-19 has apparently been transferred from animals to humans at the animal market in Wuhan, China. COVID-19 pandemic has resulted, in addition to challenges of world public health, in significant changes and worldwide disruption affecting all aspects of human life as well as the environment [5]. As of July $26^{\text {th }}, 2020$, the cumulative number of confirmed cases of COVID-19 has exceeded 15.7 million, with about 640 thousand deaths in 216 countries or territories [11]. The worldwide disruption has resulted in numerous impacts on the environment and the climate. Some of those are positive such as (albeit likely temporary) drop in air pollution, reduction in the use of fossil fuels, and wildlife reclaiming contested habitats, while others are negative such as growing piles of infected waste like tissues, old face masks and overuse of water.

The aim of this paper is to look at the environmental impacts and consequences of COVID-19 pandemic in urban areas backed up by collected data (post-pandemic) and comparing them with pre-pandemic existing data for urban centers in Iran as a case study. Most recently published articles such as Kerimray et al. (2020), Lal et al. (2020) and Wang and Su (2020) have mainly discussed the impact on air quality and its improvement due to lockdown during pandemic at different parts of the world [5] [16] [20]. In this paper, other environmental aspects have been evaluated as well. Outcomes of such studies could be beneficial in planning management strategies to cope with post-pandemic environmental impacts in the future. 


\section{Background Information}

The map of IR Iran as well as the statistics from the World Health Organization (WHO) in terms of number of confirmed cases and deaths due to COVID-19 is presented in Figure 2. Similar to most other countries, the government of IR Iran initially implemented a lockdown in order to control the pandemic. However, since the IR Iran economy was already experiencing negative growth rate and high inflation due to the United States' 2018 withdrawal from the nuclear deal and re-imposition of sanctions, the lockdown ended towards the end of April and businesses resumed their activity. This has resulted in a second wave of COVID-19 infections and outbreak, as seen in Figure 2, and the IR Iranian government implemented partial lockdown in parts of the country again.

\section{Direct and Indirect Negative Effects of Coronavirus Pandemic in Urban Areas}

\subsection{Residential and Medical Waste}

The COVID-19 outbreak poses many challenges to solid waste management in urban areas. The high demand for disposable medical products due to coronavirus has led to an increase in medical waste generation. For example, in Wuhan, China, with over than 11 million people, which was the epicenter of the new Coronavirus, the amount of medical (hazardous) waste at the peak of Corona disease rose from 40 to 240 tons per day, much more than the amount that the city's only dedicated facility can incinerate per day [21]. Not only this brings many environmental problems, but it also puts workers, cleaners, and other individuals who have to spend a lot of time in public places or in the waste collection and disposal industry at risk as infected collected waste during a pandemic might facilitate the spread of COVID-19 [1]. Therefore, employing security

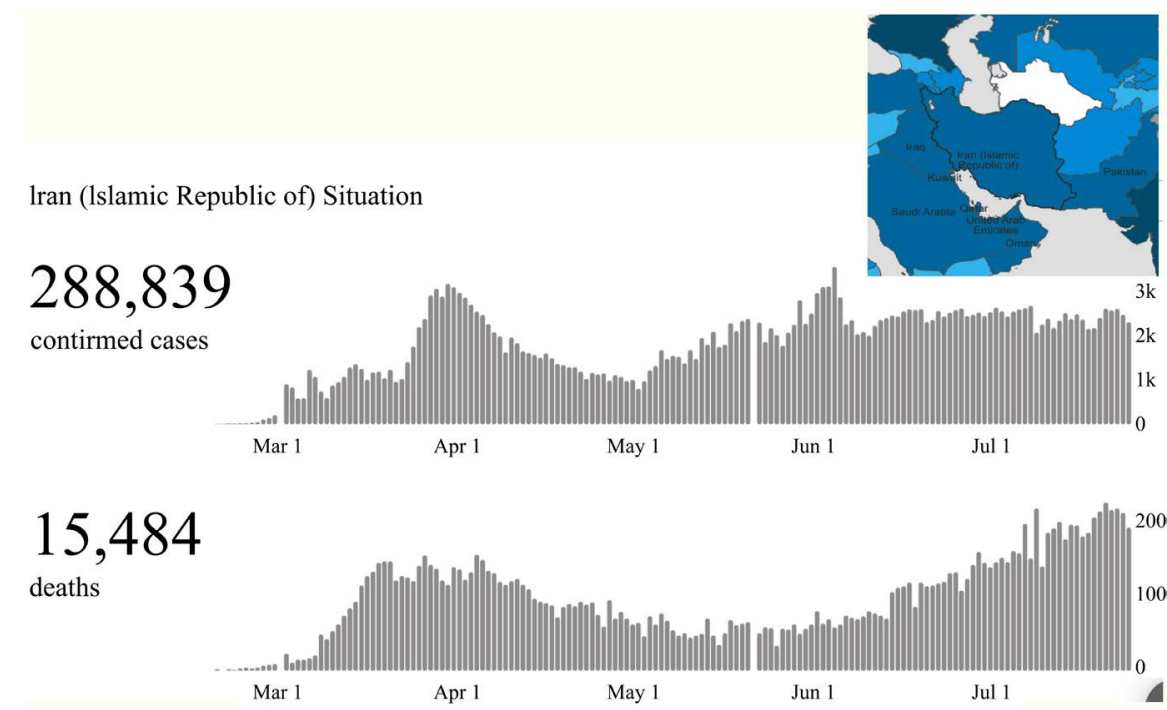

Figure 2. Map of Iran and number of confirmed and deaths due to COVD-19 pandemic [11]. 
measures to protect the health and safety of employers and providing them assurance about how workers are decreasing the risks of Coronavirus crisis are crucial for ensuring continuity of waste management services. Another related issue in addition to the huge increase in generation of personal protection equipment wastes such as gloves and masks is that these products could be contaminated. Thus, this type of waste can be a $\mathrm{c}$ and infect other waste with the virus, which means producing several thousand garbage infected with the Coronavirus. Therefore, special measures must be taken to properly secure or incinerate these types of hazardous wastes, which will be costly. Recently, a non-governmental organization (Asian Ocean Environment) conducted a study in Hong Kong where a large number of disposable masks were thrown away, covering up to 100 meters from the beach. The adverse effects of such medical waste will appear in the future. When they enter the natural habitat of animals (land and ocean), they could get consumed by animals leading to infection or death [22].

In addition to medical waste, the volume of non-recyclable municipal waste also increased significantly, and the disposal of this waste required more landfill space, which in turn poses many challenges for the environment [23] [24] [25] [26]. For example, plastic packaging has soared in popularity during the coronavirus pandemic perceived as a more sanitary option, food shoppers have resumed using plastic bags for packaging food products at checkout points citing health concerns over reusable bags by consumers. Furthermore, due to quarantine policies, many people have increased their consumption of take-away food delivered with plastic packaging, which has led to an increase in the amount of non-biodegradable wastes and ultimately contamination of water and oceans.

The sharp decline in agricultural and fisheries exports has also resulted in the accumulation of piles of organic waste. Local waste problems have risen as many municipalities have suspended their recycling activities out of fear of spreading the virus to recycling centers. All of these developments have brought disastrous challenges for the waste management industries and authorities, and subsequently for the environment. With the advent of import restrictions on export markets and the sharp decline in the availability of freight forwarding services, the Coronavirus crisis has caused a rise in the volume of agricultural and nonportable fishery commodities. Many export-oriented manufacturers produce large quantities to make the product attractive to local markets, and thus organic waste levels have climbed significantly. Decayed organic wastes are expected to contribute to $\mathrm{CH}_{4}$ emissions and sharply increase during the crisis and immediately post-crisis months [27].

Based on the data collected by Iran Waste Management Organization, a rise in waste production, both for municipal and medical wastes, has occurred in Iran as well. As shown in Figure 3, during the COVID-19 pandemic the amount of both medical and household wastes increased dramatically, between $10 \%$ to $77 \%$ in some of the metropolises in Iran. This resulted in logistical problems and significantly increased the work force and collection vehicles required. Similar issues have been reported elsewhere. For example, the Ontario Waste Management 

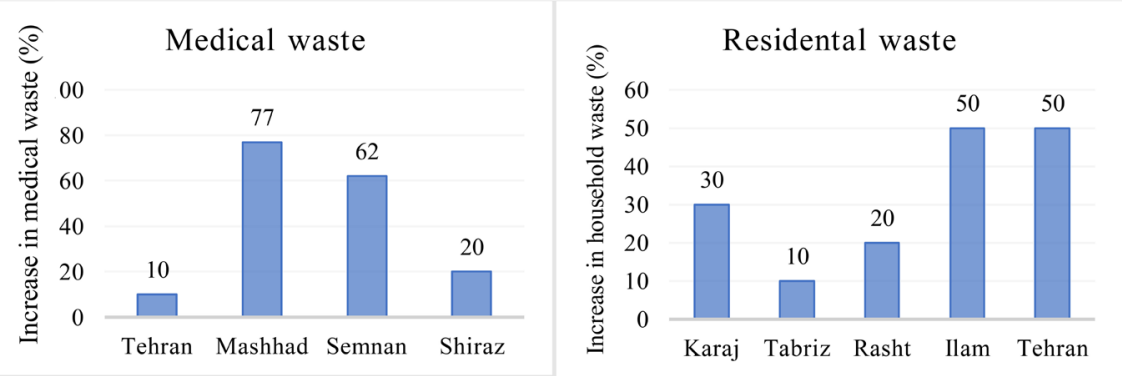

Figure 3. Increase in the amount of medical and residential waste production in different cities in Iran during the COVD-19 pandemic (Iran Waste Management Organization 2020).

Association reported that for the period of March 9 to April 13, there was a pronounced increase in residential waste compared to the same period in 2019, which is equivalent to more than 600 full waste trucks. The increased amount of waste produced not only requires more landfill space but also escalates the pandemic problem as it has been reported that solid waste could be a transmission route for COVID-19 particularly in developing countries where waste management is poor [28]. The increased quantities of infected waste also increase the risk of groundwater and soil contamination with the Coronavirus.

Al Huraimel et al. (2020) proposed some strategies to mitigate the solid waste COVID-19 related issues [1]. These include separate collection services for hot spots (residential areas with high infection rates), suspending recycling programs both at source and material recovery facilities and transporting the waste to a secured landfill or incineration facility. The best waste management strategies should be implemented to limit workers' exposure to contaminated waste as well.

\subsection{Increased Water Consumption and Wastewater Generation}

Excessive water consumption for washing and cleaning along with greater than normal sewage generation is one of the consequences caused by the Coronavirus pandemic [29]. States and cities have taken precautionary measures to ensure continuous access to clean water for drinking, washing and other uses during COVID-19. This would put more pressure and creates more demand on water and wastewater treatment and distribution systems, which would require more workers, as well as the manufacturers and suppliers who provide vital services and materials to this sector. Figure 4 shows the increase of water consumption of major cities in IR Iran during the Coronavirus pandemic. According to the chief executive officer of Tehran Water and Sewerage Company, the water consumption of Tehran, the capital, increased by 300,000 cubic meters and reached 3.1 million cubic meters per day during the outbreak of the Coronavirus, which showed $16 \%$ increase in water consumption. COVID-19 disease caused an increase in water consumption in Tabriz to reach more than 36 million liters per day. Statistics and information in Iran show a range of 10 to 40 percent increase 


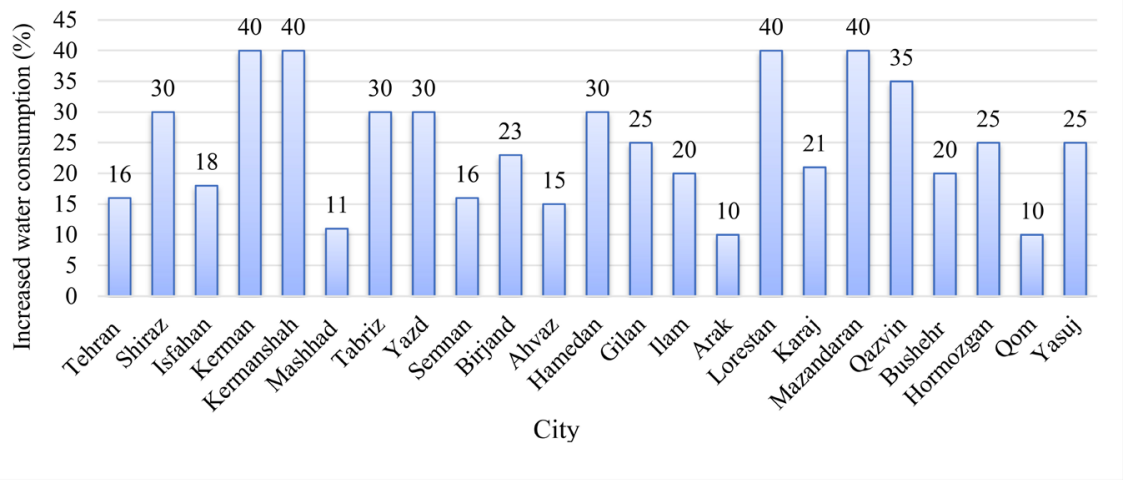

Figure 4. Increase in water consumption in different cities in Iran during the COVD-19 pandemic.

in water consumption compared to the same period in the previous years. It is worth noting that countries such as Iran with a semi-arid to arid climate, already face serious challenges with water shortage. The increase in water consumption escalates this problem to serious and critical levels. Since wastewater generation is directly related to water consumption, it could be expected that the same trend would be observed for municipal wastewater generation. This would increase the influent flowrates to the treatment plants and would affect the performance and efficiencies, which needs to be dealt with through modifying the operation.

Moreover, water and sewage, as one of the ways of transmission of the virus, must be constantly monitored and controlled. For example, studies have shown that the coronavirus has been found in the feces of some patients within three days of infection, so it can be transmitted through sewage and may be capable of causing COVID-19. However, for wastewater treatment plants with proper management and operation, the risk should be low and it is unlikely for COVID-19 to be transmitted [1]. Nevertheless, there has not been a confirmed report to support this hypothesis, standard practices associated with careful scrutiny is very important to ensure that appropriate measures are taken to treat this type of virus.

\subsection{Increased Air Pollution after the Re-Opening of the Global Economy}

Reductions in emissions from industries and transportation due to the Coronavirus economic downturn, though beneficial, should be seen as temporary and short-term. There is a strong desire to re-open the global economy and some countries have already started to allow businesses to re-open with the aim of returning to pre-pandemic economic growth rates. This fast revamping combined with trade wars and disruptions in the energy supply chain could result in excessive greenhouse gas production and will worsen its environmental effects, such as global warming, climate change and impacts on human health in urban areas. The 2008 financial crisis, for example, reduced carbon dioxide by 1 percent, but after the economy recovered, greenhouse gas emissions bounced back at a rate 
faster than before the crisis [30]. In addition, with the outbreak of the coronavirus the use of private cars, as opposed to public transit, could expand due to the risk of transmission of infectious diseases (Coronavirus) in public transportation, which could escalate air and environmental pollution. The change in travel behavior that has now occurred due to the spread of the disease can affect the style of traveling for a long time and continue even after the end of COVID-19 pandemic leading to more air pollution, city traffic and its devastating consequences.

Increasing gas emissions from factories and motor engines after the end of lockdowns not only could have significant effects on the environment but also affect human health. For instance, some dangerous components including mercury, lead, dioxins, and benzene, which are often released during the combustion of gasoline or coal could have numerous health impacts. In 2018, nine out of ten people breathed polluted air, which killed 7 million people that year [31]. Thus, if the air pollution consequences due to world's economic rapid re-launching are not managed properly, the environmental damages caused by air pollution could be more destructive than before.

\subsection{Increased Inclination to Consumption of Fossil Fuels}

Another issue is the potential increase in using fossil fuels. In recent years, researchers have sought to find alternatives to new and renewable sources of fossil fuels to mitigate global warming and greenhouse gas (GHG) emissions and to promote sustainable development. However, during the coronavirus recession, oil prices have plummeted sharply in world markets that could be bad news for the environment. Low-cost energy usually leads consumers to utilize it less efficiently and make people less inclined toward projects like retrofitting homes and offices to save energy. As industries and people, regardless of the destructive effects of fuels, are always looking for less expensive energy, there is likely to be a growing trend toward consumption of fossil fuels, as opposed to green sources, resulting in increased GHG emissions and other adverse impacts.

Coronavirus has also had destructive impacts on the climate. Lockdowns and social distancing have decelerated climate studies around the globe or ground it to a halt. For example, fieldwork everywhere has been canceled or postponed, and study flights to the Arctic have been stopped.

\subsection{Adverse Impacts on Natural Resources, Wildlife and Ecotourism}

Natural ecosystems and protected species have been at risk during the COVID-19 crisis due to temporarily reduced or lack of monitoring, management and maintenance. In many countries, environmental protection workers who are responsible for protecting national parks, land and marine conservation zones are required to stay at home during lockdown, leaving these areas unmonitored. Therefore, their absence could result in an increase in illegal deforestation, fishing and hunting of wild animals. Delays in career training, in combina- 
tion with the economic and psychological impacts of the new Coronavirus, may lead to some individuals to leave the field of conservation biology and follow other occupations that offer more stability or better income, which could result in future shortage of trained and skilled workforce in this field. Tourism industry is one the hardest hit businesses (hotels, airlines, etc.). The same applies to ecotourism. In many cases the ecotourism destinations are managed by local people and are the only source of income in these regions. With almost complete halt of this industry, following rising unemployment, could lead to the workforce to migrate from the region or to switch to harvesting the natural resources and encroachment, which in turn could have adverse impacts on natural resources and habitat of wildlife and cause environmental degradation [22]. Environmentalists predict that African countries will experience a huge rush in bushmeat poaching. According to Matt Brown of the Nature Conservancy, when there would not be any other alternative for people's income, the expectation is that poaching will go up for valuable products like rhino horn and ivory [32] [33]. It is also possible that after the re-opening of the economy and wood-dependent factories, the rate of production will increase, to compensate losses, to beyond sustainable levels which will increase deforestation [34].

\section{Direct and Indirect Positive Effects of Coronavirus on the Environment}

\subsection{Improvements in Air Quality during Pandemic}

The most obvious impact of COVID-19 pandemic during the lockdown has been the significant reduction in transportation and business activity of some specific sectors. In Italy, the largest travel restrictions have been applied since World War II. In London, almost all businesses that depend on public attendance such as cafes, restaurants, theaters and other crowded public places were completely closed, since people were asked to stay at home [35]. Flights were canceled around the world, schools and academic institutes as well as factories were closed, public transportation plummeted. All of these measures were taken to control the outbreak of the coronavirus and to reduce the mortality rate. One of the immediate positive environmental effects in urban areas was improved air quality due to reduction of air pollutant emissions [16] [25] [36] [37]. Compared to the same period in 2019, the level of air pollution in New York decreased by almost 50\%. In China, greenhouse gas emissions fell by 25 percent in early 2020 [5], factories closed and coal consumption at China's largest power plants dropped by 40 percent. China's Ministry of Ecology and Environment reported on air with good quality compared to the same period last year in more than 330 cities across China, showing an $11.4 \%$ increase. Mahato at al. (2020) evaluated the national air quality index (AQI) in Delhi, India, using 34 monitoring stations [38]. AQI reduced from 187 before lockdown to 72.6 during the lockdown showing $61 \%$ reduction in the index or improving air quality. It is worth noting that a range of $101-200$ is considered a moderately polluted AQI class while a 
range of $51-100$ is a satisfactory AQI class. Nitrogen dioxide emissions $\left(\mathrm{NO}_{2}\right)$ emissions changes were obvious in many countries [16] [20], supported by the satellite images released by NASA and the European Space Agency (ESA). Figure 5 and Figure 6 clearly show a sharp and significant reduction of $\mathrm{NO}_{2}$ concentration in North America and India.

The improvement in air quality was more palpable in developed countries due to a stronger economy, whereas in developing and undeveloped countries these changes were not as noticeable since complete shutdown of businesses and industries was not possible for their economic status. In Iran, as a developing country and the case of study, a significant decrease in air pollution during the quarantine was not observed. Figure 7 presents measured concentrations of $\mathrm{NO}_{2}$ and $\mathrm{PM}_{2.5}$ during pandemic and the same time duration in 2019. As shown in Figure 8, the main source $\mathrm{NO}_{2}$ is mobile sources, i.e., traffic related. Consequently, during the pandemic lockdown a slight decrease in the range of $15 \%$ $20 \%$ reduction in daily concentrations was observed. In the case $\mathrm{PM}_{2.5}$, the main source is fixed sources, including factories, refineries, boilers, and power plants, and no specific trend was observed.

\subsection{Reduction in Noise Pollution}

Noise is a physical form of pollution and is not life threatening. Noise pollution is the result of modern industrialized urban life and anthropological activities such as use of machines, transportation and traffic systems [43]. Even though

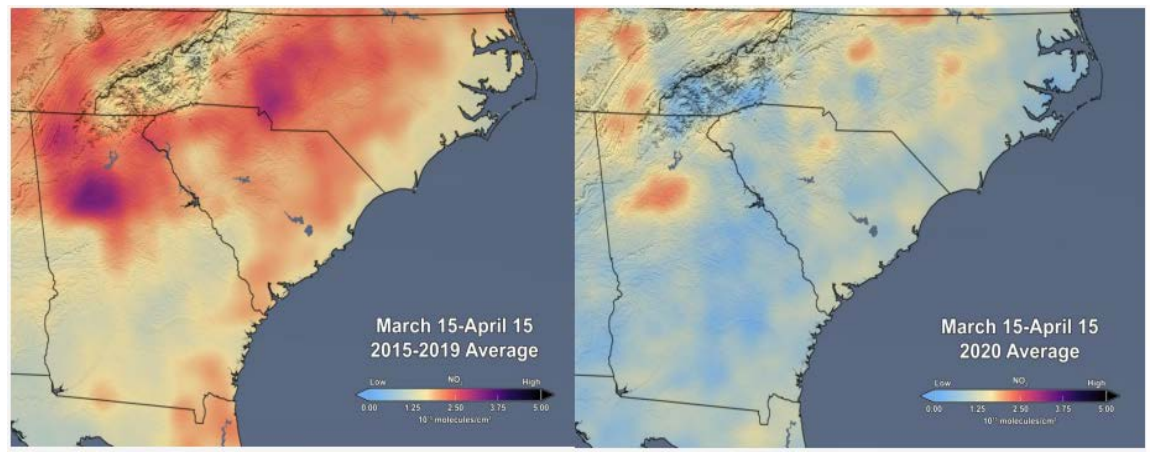

Figure 5. Evaluation of nitrogen dioxide concentration in North America [39].
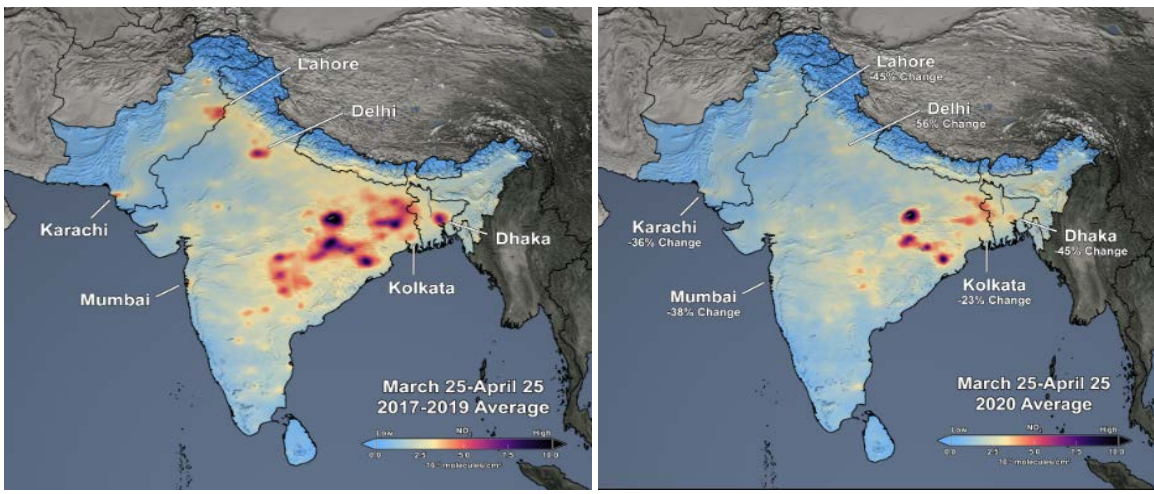

Figure 6. Evaluation of nitrogen dioxide concentration in India [40] [41]. 


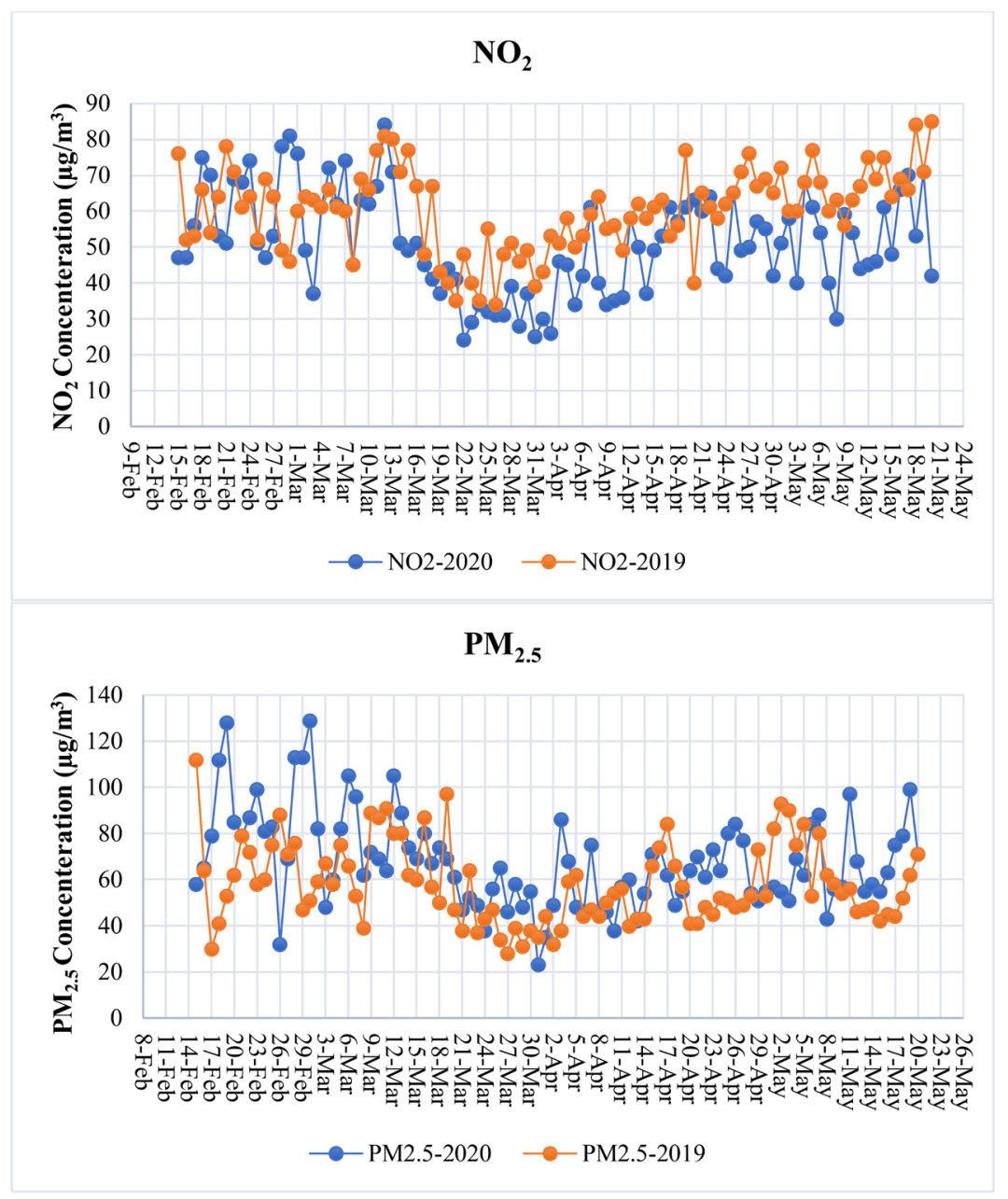

Figure 7. Daily concentrations of $\mathrm{NO}_{2}$ and $\mathrm{PM}_{2.5}$ the capital of Iran (Tehran), during the lockdown between February 15 and May 20 [42].

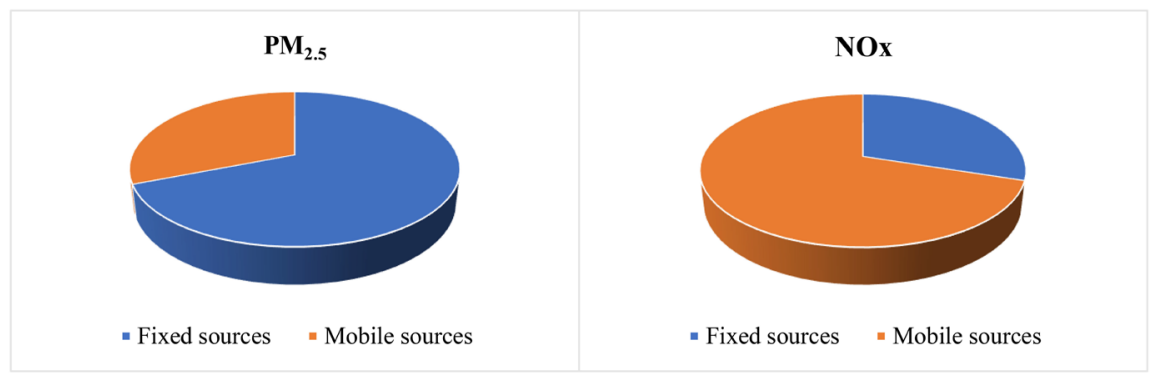

Figure 8. $\mathrm{NO}_{\mathrm{X}}$ and $\mathrm{PM}_{2.5}$ contributions to air pollution in Iran [42].

noise pollution is not fatal to human life, yet its importance cannot be overlooked. Environmental noise pollution is one of the main sources of discomfort for the population and the environment and causes health problems because repeated exposure to noise reduces the sleeping hours and productivity and efficiency of a human being and changes the natural conditions of ecosystems [44].

According to the WHO, noise levels above 65 decibels $(\mathrm{dB})$ are considered as noise pollution. Vehicles, especially personal cars are the main source of noise 
pollution in urban areas in Iran. During the lockdown measures and reduction of traffic in many counties, the use of private and public vehicles significantly reduced. This resulted in reduction of noise levels measured in Tehran, see Figure 9 , as the average daily sound level shows a decline of $1-2$ decibels during this period. It should be noted that noise level is measured on a logarithmic scale. Also, the drop around March $21^{\text {st }}$ is associated with the New Year's Eve in Iran and significant reduction in levels of traffic and urban trips. Similar results have been reported for other urban areas around the world [25] [41]. New urban management practices to combat the spread of the coronavirus, such as telecommuting, performing many daily programs, online activities and continuing this lifestyle even after the end of this period, can reduce many environmental pollutants, including noise pollution.

\subsection{Reduction in Water Pollution}

Beaches and coastal areas are one of the most important natural assets for both local residents and visitors. They provide services for recreation and tourism that are vital to the survival of coastal communities and have inherent values that must be protected from overuse [45]. However, improper management and use by people have caused many beaches around the world to suffer from pollution and adverse anthropogenic impacts including water and soil pollution, loss of marine habitat, etc. [46]. The lack of tourists and related activities such as boating as a result of the lockdown of the Coronavirus has led to significant positive changes in many coastal areas such as beaches in Acapulco, Barcelona or Salinas. In Venice, for example, water in the canals within the city was reported to be clearer and experienced greater water flow [47]. According to the Director General of Environment of Mazandaran, north of Iran, the closure of tourist centers, and the reduction of maritime transport due to COVID-19, gave the environment an opportunity to recreate. Also, the amount of effluent discharged into the sea decreased sharply, which resulted in having more opportunities for aquatic animals to spawn, and thus the Caspian Sea experienced tranquility.

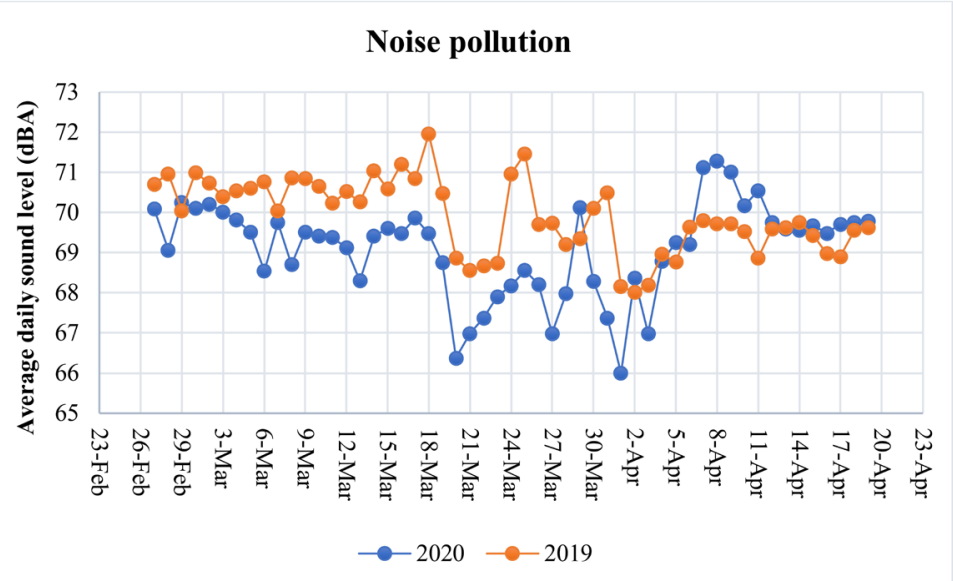

Figure 9. Comparison of the average daily sound level in fixed sound measuring stations in Tehran, Iran. 
Table 1. Imports/exports of wood products during the COVID-19.

\begin{tabular}{cc}
\hline Country & imports/exports of wood and paper products (\%) \\
\hline United State & -6 \\
Brazil & -27 \\
Chile & -24 \\
China & -20 \\
New Zealand & -17 \\
Republic of Korea & -16 \\
Japan & -14 \\
Canada & -11 \\
\hline
\end{tabular}

\subsection{Return of Tranquility to the Forests and Wildlife Habitat}

The outbreak of coronavirus and subsequent quarantine in various countries around the world has been accompanied by improved environmental conditions, wildlife and natural resources. Reducing traffic at resorts has not only revitalized the habitats of medicinal plants and improved the fertility of wildlife, but has also reduced wildlife casualties on the roads. In the United States, fatal vehicle collisions with animals such as deer, elk, moose, bears, mountain lions fell by 58\% during March and April [48]. The ban on presence and traffic in national parks and protected areas and the decrease in the presence of tourists in nature have resulted in the reduction in the destruction and seizure of natural resources, forests, reduced waste production and a return of sense of peace to national parks. Reports from environmental activists indicate that in some countries, with the streets being deserted, animals have also entered the cities.

Also, the closure of the timber industry and the reduction of exports and imports of timber have returned calm to the forests. According to statistics from January to February 2020, imports/exports of wood and paper products (including furniture) in major countries fell from $6 \%$ (US) to $27 \%$ (Brazil) compared to last year (Table 1). Among the countries that have experienced this decline are Chile $(-24 \%)$, China $(-20 \%)$, New Zealand $(-17 \%)$, the Republic of Korea $(-16 \%)$, Japan $(-14 \%)$ and Canada $(-11 \%)$ [34].

\section{Conclusion}

COVID-19 has led to tremendous environmental changes and impacts. This research comprehensively presented some positives and negatives instances, on all aspects of the new coronavirus pandemic on the environment, especially directing the environment of Iran from the perspective of time and space. Knowledge of the type and the magnitude of these impacts is critical in management, planning and decision making during such pandemic events. Significant reduction of traffic and economic activities results in positive effects such reduction in greenhouse gas emission, energy consumption, noise pollution, etc., particularly in wealthy developed countries. However, there are also adverse environmental 
consequences such as increased quantities of solid waste, increased water demand, and the lack of management and monitoring of natural ecosystems. Furthermore, it should be noted that the positive impacts of the coronavirus epidemic not only are all likely to be temporary and it is currently not clear how conservation will fare in the aftermath of the pandemic, but may also worsen environmental conditions after the re-opening of industries, factories and transportation. Overall, results of such studies help understand the pandemic related issues in the environmental context. This would help decision makers in planning mitigation plans for future pandemics. Hence, the current coronavirus pandemic is both an opportunity and a threat. It is an opportunity to revisit the lesser-known threats to strengthen and plan for the future. Governments, communities and companies can and should use the opportunity to see how we got here, what is not working, and ask how we can plan better for our future.

\section{Conflicts of Interest}

The authors declare no conflicts of interest regarding the publication of this paper.

\section{References}

[1] Al Huraimel, K., Alhosani, M., Kunhabdulla, S. and Stietiya, M.H. (2020) SARS-CoV-2 in the Environment: Modes of Transmission, Early Detection and Potential Role of Pollutions. Science of The Total Environment, 744, Article ID: 140946. https://doi.org/10.1016/j.scitotenv.2020.140946

[2] Chein, L.C. and Chen, L.W. (2020) Meteorological Impacts on the Incidence of COVID-19 in the U.S. Stochastic Environmental Research and Risk Assessment, 34, 1675-1680. https://doi.org/10.1007/s00477-020-01835-8

[3] Langousis, A. and Carsteanu, A.A. (2020) Undersampling in Action and at Scale: Application to the COVID-19 Pandemic. Stochastic Environmental Research and Risk Assessment, 34, 1281-1283. https://doi.org/10.1007/s00477-020-01821-0

[4] Pramanik, M., Udmale, P., Bisht, P., Chowdhury, K., Szabo, S. and Pal, I. (2020) Climatic Factors Influence the Spread of COVID-19 in Russia. International Journal of Environmental Health Research, 1-6. https://doi.org/10.1080/09603123.2020.1793921

[5] Wang, Q. and Su, M. (2020) A Preliminary Assessment of the Impact of COVID-19 on Environment-A Case Study of China. Science of the Total Environment, 728, Article ID: 138915. https://doi.org/10.1016/j.scitotenv.2020.138915

[6] Saadat, S., Rawtani, D. and Hussain, C.M. (2020) Environmental Perspective of COVID-19. Science of the Total Environment, 728, Article ID: 138870. https://doi.org/10.1016/j.scitotenv.2020.138870

[7] Kooraki, S., Hosseiny, M., Myers, L. and Gholamrezanezhad, A. (2020) Coronavirus (COVID-19) Outbreak: What the Department of Radiology Should Know. Journal of the American College of Radiology, 17, 447-451. https://doi.org/10.1016/j.jacr.2020.02.008

[8] Tyrrell, D.A. and Bynoe, M.L. (1966) Cultivation of Viruses from a High Proportion of Patients with Colds. Lancet, 287, 76-77. https://doi.org/10.1016/S0140-6736(66)92364-6

[9] Ather, A., Patel, B., Ruparel, N.B., Diogenes, A. and Hargreaves, K.M. (2020) Reply 
to "Coronavirus Disease 19 (COVID-19): Implications for Clinical Dental Care". Journal of Endodontics, 46, 1342. https://doi.org/10.1016/j.joen.2020.08.005

[10] Kucharski, A.J., Russell, T.W., Diamond, C., Liu, Y., Edmunds, J., Funk, S. and Eggo, R.M. (2020) Early Dynamics of Transmission and Control of COVID-19: A Mathematical Modelling Study. The Lancet Infectious Diseases, 20, 553-558. https://doi.org/10.1016/S1473-3099(20)30144-4

[11] World Health Organization (WHO) (2020) Coronavirus Disease (COVID-19) Pandemic. https://www.who.int/emergencies/diseases/novel-coronavirus-2019

[12] Center for Disease Control and Prevention (2012) First Global Estimate of 2009 H1N1 Pandemic Mortality Released by CDC Led Collaboration. https://www.cdc.gov/flu/spotlights/pandemic-global-estimates.htm

[13] Center for Disease Control and Prevention (1994) Human Plague-United States, 1993-1994. Morbidity and Mortality Weekly Report, 43, 242-246. http://www.cdc.gov/mmwr/preview/mmwrhtml/00026077.htm

[14] National Geographic Society (2020) Plague: The Black Death. https://www.nationalgeographic.com/science/article/the-plague

[15] Little, L. and Jan, K. (2008) Plague and the End of Antiquity: The Pandemic of 541-750. Cambridge University Press, New York.

[16] Lal, P., Kumar, A., Kumar, S., Kumari, S., Saikia, P., Dayanandan, A., Adhikari, D. and Khan, M.L. (2020) The Dark Cloud with a Silver Lining: Assessing the Impact of the SARS COVID-19 Pandemic on the Global Environment. Science of the Total Environment, 732, Article ID: 139297. https://doi.org/10.1016/j.scitotenv.2020.139297

[17] Roberts, M. (2009) Flu Virus with 'Pandemic Potential' Found in China. BBC News https://www.bbc.com/news/health-53218704

[18] Science Daily (2013) Article on Spanish Flue. https://www.sciencedaily.com/releases/2013/03/130307190637.htm

[19] The New York Times (2009) Mexican President Tries to Isolate Those with Swine Flu. https://www.nytimes.com/2009/04/26/world/americas/26mexico.html

[20] Kerimray, A., Baimatova, N., Ibragimova, O.P., Bukenov, B., Kenessov, B., Plotitsyn, P. and Karaca, F. (2020) Assessing Air Quality Changes in Large Cities during COVID-19 Lockdowns: The Impacts of Traffic-Free Urban Conditions in Almaty, Kazakhstan. Science of the Total Environment, 730, Article ID: 139179. https://doi.org/10.1016/j.scitotenv.2020.139179

[21] South China Morning Post (2020) South China Morning Post: Coronavirus Leaves China with Mountains of Medical Wast.

[22] Hellewell, J., Abbott, S., Gimma, A., Bosse, N.I., Jarvis, C.I., Russell, T.W., Munday, J.D., Kucharski, A.J., Edmunds, W.J., Funk, S. and Eggo, R.M. (2020) Feasibility of Controlling COVID-19 Outbreaks by Isolation of Cases and Contacts. The Lancet Global Health, 8, 488-496. https://doi.org/10.1016/S2214-109X(20)30074-7

[23] Mourad, M. (2016) Recycling, Recovering and Preventing "Food Waste": Competing Solutions for Food Systems Sustainability in the United States and France. Journal of Cleaner Production, 126, 461-477. https://doi.org/10.1016/j.jclepro.2016.03.084

[24] Schanes, K., Dobernig, K. and Gözet, B. (2018) Food Waste Matters-A Systematic Review of Household Food Waste Practices and Their Policy Implications. Journal of Cleaner Production, 182, 978-991. https://doi.org/10.1016/j.jclepro.2018.02.030

[25] Zambrano-Monserrate, M.A., Ruano, M.A. and Sanchez-Alcalde, L. (2020) Indirect 
Effects of COVID-19 on the Environment. Science of The Total Environment, 728, Article ID: 138813. https://doi.org/10.1016/j.scitotenv.2020.138813

[26] Rezaeitavabe, F., Saadat, S., Talebbeydokhti, N., Sartaj, M. and Tabatabaei, M. (2020) Enhancing Bio-Hydrogen Production from Food Waste in Single-Stage Hybrid Dark-Photo Fermentation by Addition of Two Waste Materials (Exhausted Resin and Biochar). Biomass and Bioenergy, 143, Article ID: 105846.

https://doi.org/10.1016/j.biombioe.2020.105846

[27] Hamwey, R. (2020) Environmental Impacts of Coronavirus Crisis, Challenges Ahead. United Nations Conference on Trade and Development, Geneva.

[28] Mol, M.P.G. and Caldas, S. (2020) Can the Human Coronavirus Epidemic Also Spread through Solid Waste? Waste Management \& Research, 38, 485-486. https://doi.org/10.1177\%2F0734242X20918312

[29] Sivakumar, B. (2020) COVID-19 and Water. Stochastic Environmental Research and Risk Assessment, 35, 531-534. https://doi.org/10.1007/s00477-020-01837-6 https://www.ncbi.nlm.nih.gov/pmc/articles/PMC7346856/

[30] Science Daily (2011) Carbon Dioxide Emissions Rebound Quickly after Global Financial Crisis. https://www.sciencedaily.com/releases/2011/12/111205140613.htm

[31] World Health Organization (WHO) (2018) 9 Out of 10 People Worldwide Breathe Polluted Air, but More Countries Are Taking Action.

https://www.who.int/news-room/detail/02-05-2018-9-out-of-10-people-worldwidebreathe-polluted-air-but-more-countries-are-taking-action

[32] Deliso, M. (2020) Conservationists Fear African Animal Poaching Will Increase during COVID-19 Pandemic.

https://abcnews.go.com/International/conservationists-fear-african-animal-poachin g-increase-covid-19/story?id=70118142

[33] CNBC (2020) Filthy Bloody Business:' Poachers Kill More Animals as Coronavirus Crushes Tourism to Africa.

https://www.cnbc.com/2020/04/24/coronavirus-poachers-kill-more-animals-as-tour ism-to-africa-plummets.html

[34] Food and Agricultural Organization of the United Nations (2020) The Impacts of COVID-19 on the Forest Sector: How to Respond? Food and Agricultural Organization of the United Nations, Rome.

[35] Harapan, H., Itoh, N., Yufika, A., Winardi, W., Keam, S., Te, H., et al. (2020) Coronavirus Disease 2019 (COVID-19): A Literature Review. Journal of Infection and Public Health, 13, 667-673. https://doi.org/10.1016/j.jiph.2020.03.019

[36] McPherson, G.R. (2020) The Means by Which COVID-19 Could Cause Extinction of All Life on Earth. Journal of Environmental Analysis \& Ecology Studies, 745, Article ID: 141022.

[37] Kumari, P. and Toshniwal, D. (2020) Impact of Lockdown Measures during COVID-19 on Air Quality-A Case Study of India. International Journal of Environmental Health Research. https://doi.org/10.1080/09603123.2020.1778646

[38] Mahato, S., Pal, S. and Ghosh, K.P. (2020) Effect of lockdown amid COVID-19 pandemic on air quality of the megacity Delhi, India. Science of The Total Environment, 730, Article ID: 139086. https://doi.org/10.1016/j.scitotenv.2020.139086

[39] ESA (European Space Agency) (2020). https://airquality.gsfc.nasa.gov/slider/pandemic-and-after-southeast-us-2015-2019versus-2020

[40] ESA (European Space Agency) (2020) Pandemic Before and After: South Asia: 2017-2019 versus 2020. 
https://airquality.gsfc.nasa.gov/slider/pandemic-and-after-south-asia-2017-2019-ver sus-2020

[41] Arora, S., Bhaukhandi, K.D. and Mishra, P.K. (2020) Coronavirus Lockdown Helped the Environment to Bounce Back. Science of the Total Environment, 742, Article ID: 140573. https://doi.org/10.1016/j.scitotenv.2020.140573

[42] Iran National Air Pollution Monitoring System (2020). http://aqms.doe.ir/

[43] Hogan, C.M. andLatshaw, G.L. (1973) The Relationship between Highway Planning and Urban Noise. Proceedings of the ASCE Urban Transportation Division Environment Impact Specialty Conference, Chicago, 21-23 May 1973, 109-126.

[44] Zambrano-Monserrate, M.A., Silva-Zambrano, C.A. and Ruano, M.A. (2018) The Economicvalue of Natural Protected Areas in Ecuador: A Case of Villamil Beach National Recreation Area. Ocean \& Coastal Management, 157, 193-202. https://doi.org/10.1016/j.ocecoaman.2018.02.020

[45] Lucrezi, S., Saayman, M. and Van der Merwe, P. (2016) An Assessment Tool for Sandy Beaches: A Case Study for Integrating Beach Description, Human Dimension, and Economic Factors to Identify Priority Management Issues. Ocean \& Coastal Management, 121, 1-22. https://doi.org/10.1016/j.ocecoaman.2015.12.003

[46] Partelow, S., Von Wehrden, H. and Horn, O. (2015) Pollution Exposure on Marine Protected Areas: A Global Assessment. Marine Pollution Bulletin, 100, 352-358. https://doi.org/10.1016/j.marpolbul.2015.08.026

[47] CNN (Cable News Network) (2020) Jellyfish Seem Swimming in Venice's Canals. https://www.cnn.com/travel/article/jellyfish-venice/index.html

[48] Katz, C. (2020) Roadkill Rates Fall Dramatically as Lockdown Keeps Drivers at home. National Geographic.

https://www.nationalgeographic.com/animals/2020/06/decline-road-kill-pandemiclockdown-traffic/ 